\title{
Methods for Prediction of Temperature Distribution in Flashover Caused by Backdraft Fire
}

\author{
Guowei Zhang, ${ }^{1,2}$ Guoqing Zhu, ${ }^{1}$ Guanglin Yuan, ${ }^{2}$ and Lili Huang ${ }^{3}$ \\ ${ }^{1}$ School of Safety Engineering, China University of Mining and Technology, Xuzhou 221116, China \\ 2 Jiangsu Key Laboratory for Environmental Impact and Structural Safety in Civil Engineering, Xuzhou 221116, China \\ ${ }^{3}$ Institute of Industry Technology, Guangzhou and Chinese Academy of Sciences, Guangzhou 510000, China
}

Correspondence should be addressed to Guoqing Zhu; zhangguoweiboy@126.com

Received 29 December 2013; Accepted 22 May 2014; Published 4 June 2014

Academic Editor: Mohamed A. Seddeek

Copyright (C) 2014 Guowei Zhang et al. This is an open access article distributed under the Creative Commons Attribution License, which permits unrestricted use, distribution, and reproduction in any medium, provided the original work is properly cited.

\begin{abstract}
Accurately predicting temperature distribution in flashover fire is a key issue for evacuation and fire-fighting. Now many good flashover fire experiments have be conducted, but most of these experiments are proceeded in enclosure with fixed openings; researches on fire development and temperature distribution in flashover caused by backdraft fire did not receive enough attention. In order to study flashover phenomenon caused by backdraft fire, a full-scale fire experiment was conducted in one abandoned office building. Process of fire development and temperature distribution in room and corridor were separately recorded during the experiment. The experiment shows that fire development in enclosure is closely affected by the room ventilation. Unlike existing temperature curves which have only one temperature peak, temperature in flashover caused by backdraft may have more than one peak value and that there is a linear relationship between maximum peak temperature and distance away from fire compartment. Based on BFD curve and experimental data, mathematical models are proposed to predict temperature curve in flashover fire caused by backdraft at last. These conclusions and experiment data obtained in this paper could provide valuable reference to fire simulation, hazard assessment, and fire protection design.
\end{abstract}

\section{Introduction}

Fire disaster, especially flashover, is one of the most hazard accidents in buildings. Flashover caused by backdraft is one especial phenomenon which is important for evacuation and fire-fighting. Fire in the enclosure without openings grows and generates increasing energy after ignition. With oxygen depletion in the fire development, fire releases decreasing energy and may stop developing. However, pyrolysis is still in a relatively high rate and causes accumulation of flammable gases. At this time, if one opening is created, such as one window breaks, fresh air would flow in through opening and cause backdraft to happen. Then the fire may grow toward flashover and the smoke would flow into corridor and subside. As remarked above, we can deduce that the flashover caused by backdraft is different from that in fixed openings enclosure fire and there should be a decay stage before flashover for oxygen depletion. So we can hold that temperature in flashover fire caused by backdraft could not be accurately described as existing temperature curves, such as ISO 834 curve, ASTM-E119 curve, external fire curve, and hydrocarbon curve [1-3].

Now many good studies on flashover fire experiments have be conducted, but most of these experiments were proceeded in enclosure with fixed openings, which mainly focused on the criterion for flashover, mechanism of flashover, and models for flashover hazard calculations [4-18]. Meanwhile, some researches on backdraft have also been carried out and lots of useful achievements have been made. Those studies are mainly confined to the experimental recurrence and numerical simulation of backdraft caused by the combustion of gas or liquid fuels, and the relevant theoretical studies are generally limited to the catastrophic behaviors [19-25]. But there have been very few reports of study on the flashover caused by backdraft. The full-scale experiment is seldom done to study fire development and temperature distribution.

In order to study the temperature distribution in flashover fire caused by backdraft, one full-scale room fire in one 


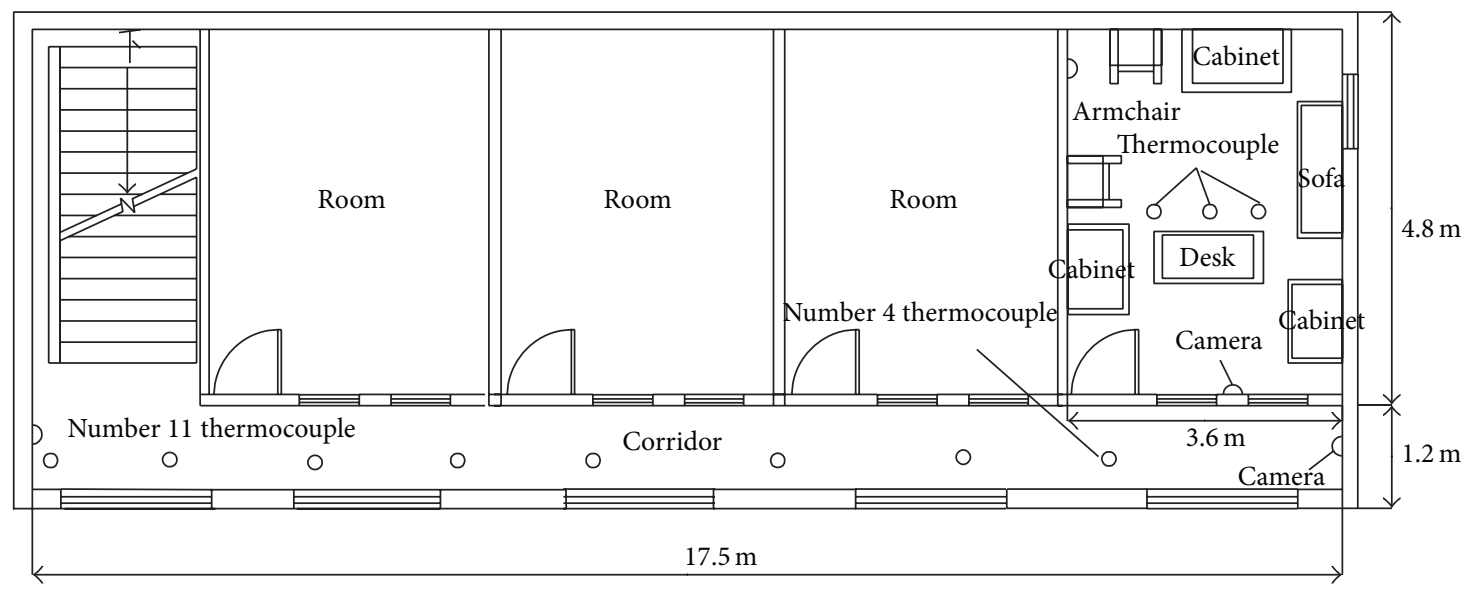

FIGURE 1: The planar graph of experiment building.
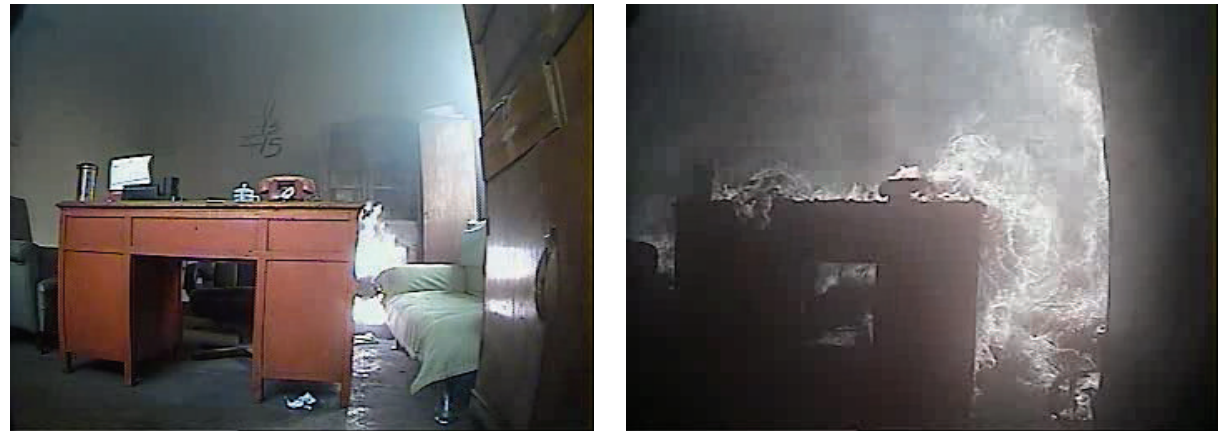

FIGURE 2: Fire spread in the room (at $112 \mathrm{~s}$ and $930 \mathrm{~s}$ ).

three-storey office building was taken out. Process of fire development and temperature distribution in room and corridor were separately recorded during the experiment. Based on the "BFD curve," an empirical correlation is built to predict the temperature distribution in flashover fire caused by backdraft by observing experimental phenomenon and analyzing temperature data.

\section{Experiment Design}

Full-scale fire experiment was conducted in a disused threestorey office building $(17.5 \mathrm{~m} \times 6.0 \mathrm{~m} \times 10.0 \mathrm{~m})$ located in Xuzhou city, China. The room for experiment $(3.6 \mathrm{~m} \times$ $4.8 \mathrm{~m}$ ) was located in the east side of building with $0.2 \mathrm{~m}$ thick concrete wall as shown in Figure 1. Meanwhile, in the experimental room wall, there were one southern door $(0.8 \mathrm{~m} \times 2.3 \mathrm{~m})$, one northeast window $(1.0 \mathrm{~m} \times 2.0 \mathrm{~m})$, and two southern windows $(0.8 \mathrm{~m} \times 2.0 \mathrm{~m})$. There were also five high windows with 2.0 width and $2.0 \mathrm{~m}$ height in the outside wall of the corridor.

As furniture arrangement in common office building, combustible in the experiment room were one leather sofa (weighing $21.5 \mathrm{~kg}$ ), one wooden desk (weighing $49.2 \mathrm{~kg}$ ), two leather armchairs (each armchair weighing $32.3 \mathrm{~kg}$ ), three wooden cabinets (each cabinet weighing $84.7 \mathrm{~kg}$ ), some papers (weighing $14.1 \mathrm{~kg}$ ), and clothing (weighing $15.7 \mathrm{~kg}$ ), shown in Figure 1 too.
The details of experimental installation can also be found in Figure 1. Three k-thermocouples numbered 1 3, $2.0 \mathrm{~m}$ distance of each other, were placed at central position of experiment room $0.5 \mathrm{~m}$ below ceiling. Furthermore, to measure smoke temperature in corridor, eight k-thermocouples numbered 4 11, $2.0 \mathrm{~m}$ distance of each other, were placed at corridor center $0.5 \mathrm{~m}$ below ceiling. As shown in Figure 1, number 4 thermocouple was the nearest one to the experimental room while the number 11thermocouple was the farthest one. All data of these collected thermocouples would be sent to computers by Agilent 34970a data collecting card. Meanwhile, two cameras were necessities for image acquisition in the fire experiment, one in the experiment room and another in the corridor.

\section{Experiment Result and Discussion}

The whole fire experiment (shown in Figures 2, 3, and 4), from ignition to extinction, lasted approximately $1800 \mathrm{~s}$. At $10 \mathrm{~s}$, one quilt located in one northern cabinet was ignited and room opening was closed. At $112 \mathrm{~s}$, fire spread from quilt to the cabinet. And then fire stopped developing. At 675 s, glass of northeast windows was broken and fire overall spread the cabinet. Thus, backdraft happened. And then, flame sprang out of the door. At $825 \mathrm{~s}$, a small broken hole appeared in one of south window glass. At 907 s, fire spread from cabinet to 

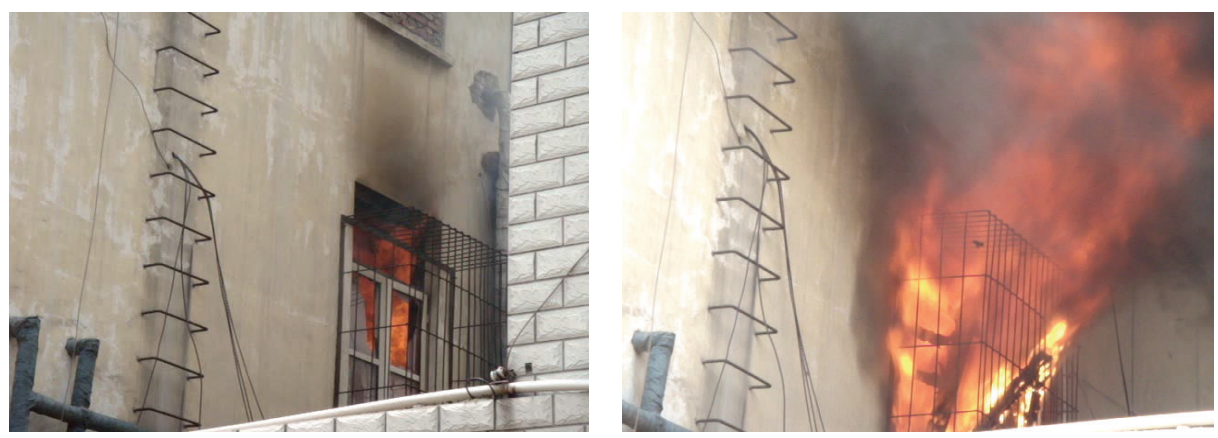

Figure 3: Glass broken and fire sprang outdoor (at $675 \mathrm{~s}$ and $930 \mathrm{~s}$ ).
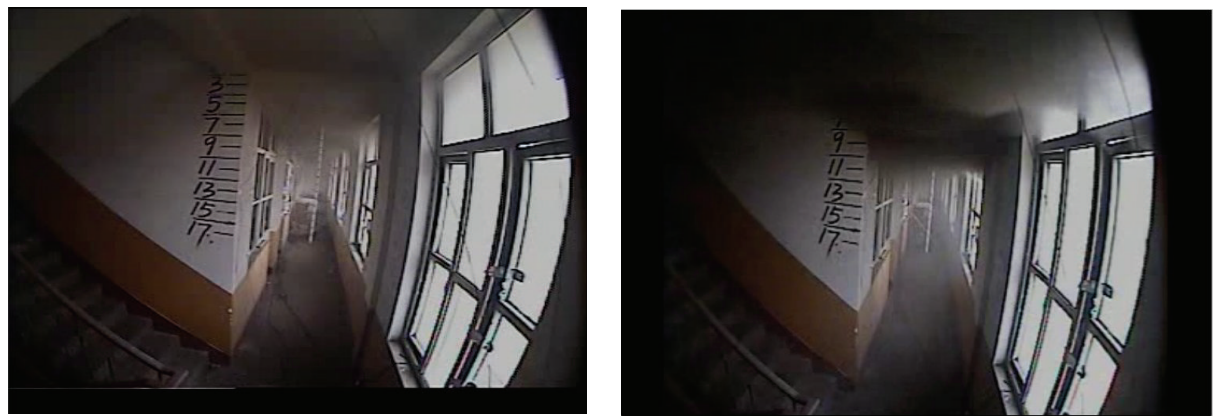

FIgURE 4: Smoke spread in the corridor (at $400 \mathrm{~s}$ and $1075 \mathrm{~s}$ ).

the nearest sofa. At $930 \mathrm{~s}$, flashover occurred in fire room and all the combustible materials in the enclosure are involved in the fire. At $932 \mathrm{~s}$, all glasses of south window were broken and lots of smoke waft across corridor. After flashover, the room fire developed into fully developed stage and flames extended out through the opening. At $1075 \mathrm{~s}$, one $0.7 \mathrm{~m}$ thickness smoke layer had formed in the corridor. As the fuel becomes consumed, the energy release rate diminished and the fire stepped into decay stage.

3.1. Fire Compartment Temperature. As shown in Figure 5, fire compartment temperature rose fast at $200 \mathrm{~s}$ and then quickly reached first temperature peak about $374^{\circ} \mathrm{C}$ at $336 \mathrm{~s}$. After that, the temperature decreased to $111^{\circ} \mathrm{C}$ for oxygen deficiency at 632 s. At 675 s, as we described above, glass in the northeast window was broken and backdraft happened; therefore, the temperature rose again. Meanwhile, owing to the flashover and supply complement of fresh air, the temperature quickly reached the second temperature peak at about $887^{\circ} \mathrm{C}$. Then the temperature in the room kept one relatively stable value at fully developed stage. With combustible burnt out, the temperature decreased again at decay stage.

From fire compartment temperature, we can draw one conclusion that the temperature in flashover fire caused by backdraft is different from that in fixed opening flashover fire without stable oxygen supply. Fire compartment temperature is closely affected by the room ventilation. When ventilation factor is equal to zero, the temperature in enclosure fire would

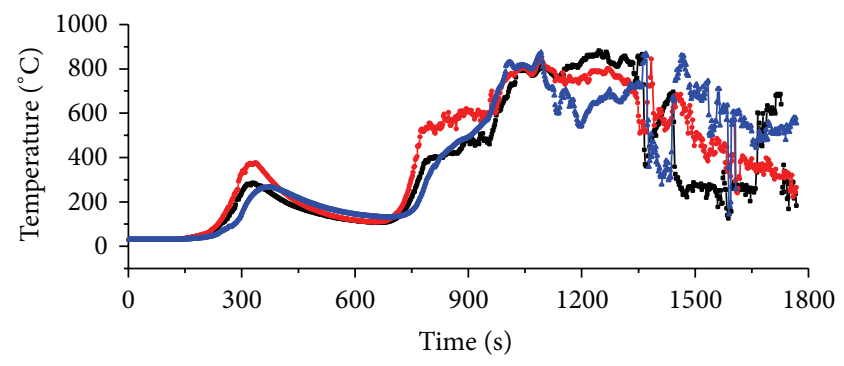

-.- Number 1 thermocouple -.- Number 3 thermocouple -.- Number 2 thermocouple

FIGURE 5: Fire compartment temperature in the experiment.

firstly rise and then decrease for the fact that the fire is suppressed for lack of oxygen. When some opening is created, temperature may rise again and then reach the maximum temperature at about $887^{\circ} \mathrm{C}$ after flashover.

3.2. Corridor Temperature. As shown in Figure 6, corridor temperature rose fast at $825 \mathrm{~s}$ as a result of appearance of one small broken hole. Meanwhile, due to the room flashover and new opening appearance, the corridor temperature rose again and quickly reached maximum temperature peak at about $1200 \mathrm{~s}$.

Maximum temperature in corridor is one important parameter which directly affects the evacuation and fire 


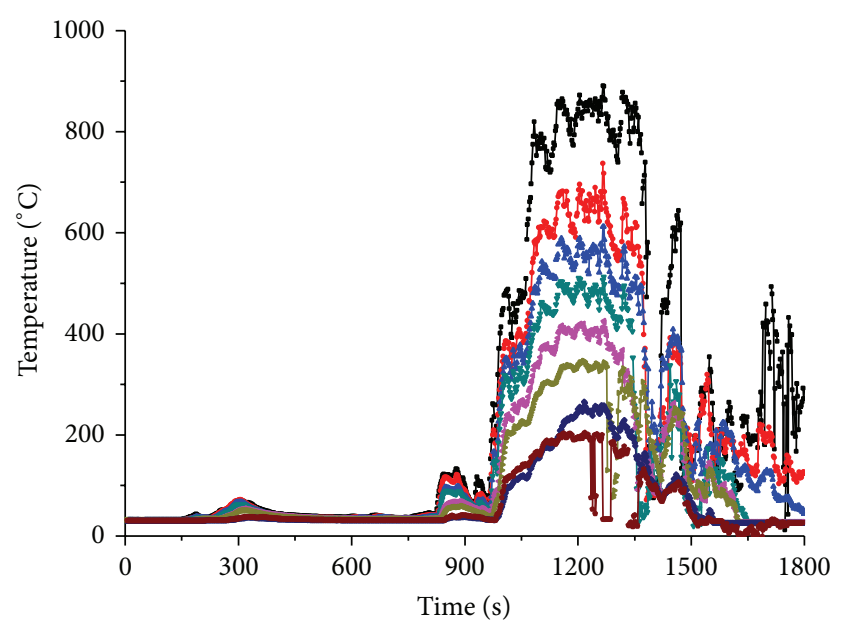

$\rightarrow$ Number 4 thermocouple $\because$ Number 8 thermocouple $\longrightarrow$ Number 5 thermocouple $\rightarrow$ Number 9 thermocouple $\rightarrow$ Number 6 thermocouple $\rightarrow$ Number 10 thermocouple $\longrightarrow$ Number 7 thermocouple $\multimap$ Number 11 thermocouple

FIgURE 6: Corridor temperature in the experiment.

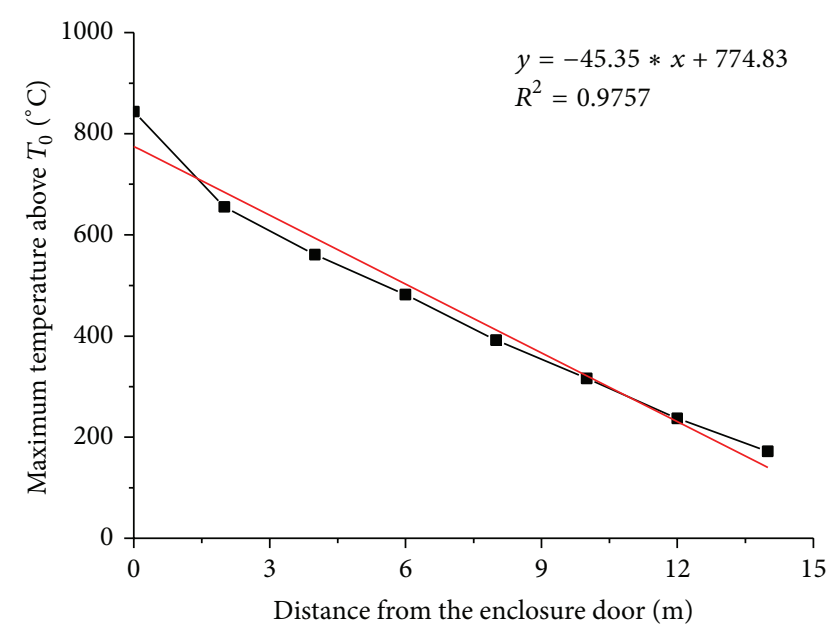

FIgURE 7: Maximum temperature above $T_{0}$ in the corridor.

spread. Now we collect maximum temperature in different locations, as is shown in Figure 7. And from that figure, we can learn that the farther the distance away from fire room, the higher the maximum temperature. By fitting, we found that there is a linear relationship between $\Delta T_{\mathrm{mL}}$ and distance with 0.9757 related coefficient and the temperature gradient in corridor is $45.35^{\circ} \mathrm{C} / \mathrm{m}$ as follows:

$$
\Delta T_{\mathrm{mL}}=774.83-45.35 x
$$

where $T_{0}$ is ambient temperature $\left({ }^{\circ} \mathrm{C}\right) ; \Delta T_{\mathrm{mL}}$ is maximum temperature above $T_{0}$ in corridor $\left({ }^{\circ} \mathrm{C}\right) ; x$ is distance away from fire room, $\mathrm{m}$.

From corridor temperature, we can see that corridor temperature rises after a certain lag time after fire. There is a linear relationship between peak temperature in corridor and distance from the enclosure door to the measurement points with $45.35^{\circ} \mathrm{C} / \mathrm{m}$ temperature gradient. Once flashover occured, hot smoke would flow into corridor and corridor temperature would exceed the tolerance limit of human body. So people in the building fire should completely evacuate to safety area before flashover occurrence.

\section{Mathematical Model}

As stated above, in flashover fire caused by backdraft, compartment temperature has more than one temperature peak, while corridor temperature rises after a certain lag time after fire. Moreover, now existing temperature curves almost have only one temperature peak and the temperature rises rapidly immediately after fire, such as ISO 834 curve, ASTM E119 curve, external fire curve, and hydrocarbon curve. But these temperature curves could not accurately describe the temperature development in varyingly ventilation flashover fire. Now, based on BFD curve presented by Barnet, as (2), an empirical correlation is proposed for predicting temperature curve in flashover fire caused by backdraft [26-28]:

$$
T=T_{0}+\Delta T_{m} \mathrm{e}^{-\ln \left(t / t_{m}\right)^{2} / s_{c}},
$$

where $T_{0}$ is ambient temperature $\left({ }^{\circ} \mathrm{C}\right) ; \Delta T_{m}$ is maximum temperature above $T_{0}\left({ }^{\circ} \mathrm{C}\right) ; t_{m}$ is time at which $\Delta T_{m}$ occurs (min); $S_{c}$ is shape constant for the curve; $S_{c}=1$ is proposed.

4.1. Empirical Correlation for Room Temperature. According to BFD curve and experimental compartment temperature shown in Figure 5, an empirical correlation is proposed for enclosure temperature in varyingly ventilation flashover fire as

$$
\begin{aligned}
& T=T_{0}+\Delta T_{m 1} \mathrm{e}^{-\ln \left(t / t_{m 1}\right)^{2} / s_{c}}, \quad t \leq t_{m 1}, \\
& T=T_{0}+\Delta T_{m 1} \mathrm{e}^{-\ln \left(\left(2 t_{m 1}-t\right) / t_{m 1}\right)^{2} / s_{c}}, \quad t_{m 1} \leq t \leq 2 t_{m 1}, \\
& T=T_{0}+\Delta T_{m 2} \mathrm{e}^{-\ln \left(\left(t-2 t_{m 1}\right) /\left(t_{m 2}-2 t_{m 1}\right)\right)^{2} / s_{c}}, \quad 2 t_{m 1} \leq t \leq t_{m 2}, \\
& T=T_{0}+\Delta T_{m 2} \mathrm{e}^{-\ln \left(\left(2 t_{m 2}-t-2 t_{m 1}\right) /\left(t_{m 2}-2 t_{m 1}\right)\right)^{2} / s_{c}}, \quad t \geq t_{m 2},
\end{aligned}
$$

where $\Delta T_{m 1}$ is maximum temperature above $T_{0}\left({ }^{\circ} \mathrm{C}\right)$ when ventilation factor is equal to zero, in other words, there are no vents in fire enclosure; $t_{m 1}$ is time at which $T_{m 1}$ occurs (min); $\Delta T_{m 2}$ is maximum temperature above $T_{0}$ after flashover $\left({ }^{\circ} \mathrm{C}\right)$; $t_{m 2}$ is time at which $T_{m 2}$ occurs (min); $S_{c}$ is shape constant for the curve; $S_{c}=1$ is proposed.

Taking $T_{0}\left(28^{\circ} \mathrm{C}\right), T_{m 1}\left(374^{\circ} \mathrm{C}\right), T_{m 2}\left(887^{\circ} \mathrm{C}\right), t_{m 1}(336 \mathrm{~s})$, and $t_{m 2}(1250 \mathrm{~s})$ into (3), an empirical correlation for room temperature is proposed to predict the room temperature, as shown in Figure 8. The prediction values coincide with the experiment data. But there is considerable difference at $t=$ $2 t_{m 1}$ and $t \geq 2 t_{m 2}-2 t_{m 1}$ which should be paid attention to in the prediction. 


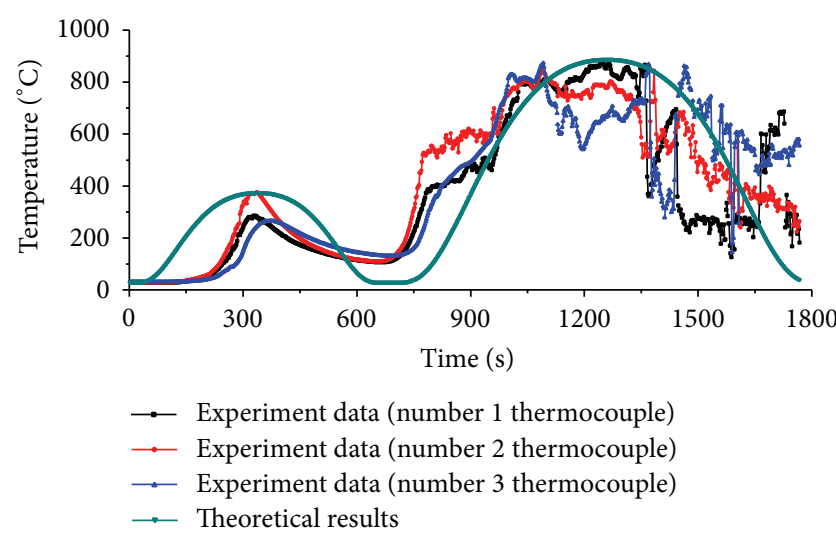

FIGURE 8: Prediction value by proposed empirical correlation and room temperature in the experiment fire.

4.2. Empirical Correlation for Corridor Temperature. According to BFD curve and corridor temperature shown in Figure 6, an empirical correlation is also proposed for corridor temperature in varyingly ventilation flashover fire as

$$
\begin{aligned}
& T=T_{0}, \quad t \leq t_{\text {exp }} \\
& T=T_{0}+\Delta T_{\mathrm{mL}} \mathrm{e}^{-\ln \left(\left(t-t_{\mathrm{exp}}\right) /\left(t_{\mathrm{mL}}-t_{\mathrm{exp}}\right)\right)^{2} / s_{c}}, \quad t_{\exp } \leq t \leq t_{\mathrm{mL}}, \\
& T=T_{0}+\Delta T_{\mathrm{mL}} \mathrm{e}^{-\ln \left(\left(2 t_{\mathrm{mL}}-t_{\exp }-t\right) /\left(t_{\mathrm{mL}}-t_{\exp }\right)\right)^{2} / s_{c}}, \quad t \geq t_{\mathrm{mL}},
\end{aligned}
$$

where $\Delta T_{\mathrm{mL}}$ is maximum temperature above $T_{0}$ in corridor $\left({ }^{\circ} \mathrm{C}\right) ; t_{\mathrm{mL}}$ is time at which $T_{\mathrm{mL}}$ occurs (min); $t_{\exp }$ is time at which glass is broken $(\mathrm{min})$. In the fire experiment, $T_{0}$ is $28^{\circ} \mathrm{C}, t_{\exp }$ is $825 \mathrm{~s}$, and $t_{\mathrm{mL}}$ is $1200 \mathrm{~s}$. Taking (1) into (4), the empirical correlation for corridor temperature in fire experiment is built, as shown in Figure 9. Using the built correlation to predict the corridor temperature, we can see that the prediction value coincides well with the experiment data. In this correlation, the temperature rising at $t_{\mathrm{m} 1}(374 \mathrm{~s})$ is ignored for that temperature rise at $t_{\mathrm{m} 1}$ is extremely small compared to temperature rise at $t_{\mathrm{mL}}$ (1200s).

\section{Conclusion}

An experimental study of fire development and temperature distribution in flashover fire caused by backdraft was conducted. Based on the experiment data and BFD curve, mathematical models are proposed at last. The major conclusions found are summarized as follows.

(1) Unlike most existing temperature curves which have only one temperature peak, temperature in flashover fire caused by backdraft has more than one temperature peak as a result of unstable oxygen supply. When ventilation factor is equal to zero, the temperature in enclosure fire would firstly rise and then decrease

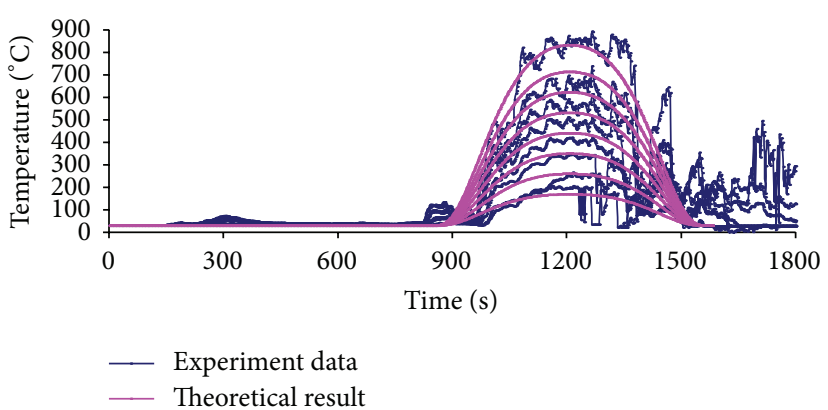

Figure 9: Prediction values by empirical correlation and corridor temperatures recorded by all thermocouples in corridor. The prediction value coincides with the experiment data.

for lack of oxygen. When some opening is created, the temperature would rise again and then reach the maximum temperature peak after flashover. The maximum temperature in flashover room is about $887^{\circ} \mathrm{C}$. Thus, if fire fighters need to break doors or windows to rescue, it is important to beware of backdraft.

(2) Corridor temperature rises after a certain lag time after fire. Owing to appearance of flashover and new opening appearance, hot smoke would flow into the corridor and then the temperature would quickly rise to maximum temperature peak. Meanwhile there is a linear relationship between peak temperature in corridor and distance from the enclosure door to the measurement points with $45.35^{\circ} \mathrm{C} / \mathrm{m}$ temperature gradient.

(3) Based on BFD curve presented by Barnet, mathematical models are proposed to predict temperature curve in flashover fire caused by backdraft. By comparing predictable value and experimental data, we can see that empirical correlations could well predict the temperature in flashover fire caused by backdraft. These conclusions and experiment data obtained in this paper could provide valuable reference to fire simulation, hazard assessment, and fire protection design.

Finally, due to limitations of experimental funding and conditions, only a full-scale fire experiment was conducted in this paper. Thus, the accuracy of these methods is still to be discussed in the next research. We will take more verification experiments, especially full-scale fire, to discuss the accuracy of this new approach in the future. Meanwhile, we will also apply the large eddy simulation to reconstruct the fire experiments and verify the accuracy of these methods by lots of simulations in the future.

\section{Conflict of Interests}

The authors declare that there is no conflict of interests regarding to the publication of this paper. 


\section{Acknowledgments}

The research presented in this paper was supported by the National Natural Science Foundation of China (Grant no. 51208504) and the open foundation of Jiangsu Key Laboratory for Environmental Impact and Structural Safety in Civil Engineering (JSKL2011YB11).

\section{References}

[1] L. C. Tsai and C. W. Chiu, "Full-scale experimental studies for backdraft using solid materials," Process Safety and Environmental Protection, vol. 91, no. 3, pp. 202-212, 2013.

[2] American Society for Testing and Materials, ASTM-119-98. Standard Test Methods for Fire Testing of Building: Construction and Materials, American Society for Testing and Materials, Philadelphia, Pa, USA, 1998.

[3] International Standard Organization, ISO 834. Fire Resistance Tests-Elements of Building Construction, International Standard Organization, Geneva, Switzerland, 1975.

[4] CEN, Hydrocarbon Curve-Section 3.2.3. Eurocode 1: Actions on Structures. Parts 1-2: General Action-Actions on Structures Exposed to Fire, EN1991-1-2, CEN, Brussels, Belgium, 2002.

[5] J. C. Jones, "On the analogy between flashover and thermal ignition," Journal of Fire Sciences, vol. 28, no. 5, pp. 487-488, 2010.

[6] C.-M. Lai, M.-C. Ho, and T.-H. Lin, "Experimental investigations of fire spread and flashover time in office fires," Journal of Fire Sciences, vol. 28, no. 3, pp. 279-302, 2010.

[7] W. G. Weng and W. C. Fan, "An inspectioyn criterion for flashover in compartment fires based on catastrophe theory," Journal of Fire Sciences, vol. 19, no. 6, pp. 413-427, 2001.

[8] V. Babrauskas, R. D. Peacock, and P. A. Reneke, "Defining flashover for fire hazard calculations: part II," Fire Safety Journal, vol. 38, no. 7, pp. 613-622, 2003.

[9] A. N. Beard, "Flashover and boundary properties," Fire Safety Journal, vol. 45, no. 2, pp. 116-121, 2010.

[10] P. G. Holborn and S. R. Bishop, "Experimental and theoretical models of flashover," Fire Safety Journal, vol. 21, no. 3, pp. 257266, 1993.

[11] W. K. Chow, "Study on the flashover criteria for compartmental fires," Journal of Fire Sciences, vol. 15, no. 2, pp. 95-107, 1997.

[12] T. L. Graham, G. M. Makhviladze, and J. P. Roberts, "Flashover and the effects of compartment scale," Journal of Applied Fire Science, vol. 7, no. 2, pp. 115-128, 1997.

[13] S. Jolly and K. Saito, "Scale modeling of fires with emphasis on room flashover phenomenon," Fire Safety Journal, vol. 18, no. 2, pp. 139-182, 1992.

[14] V. Novozhilov, "Flashover control under fire suppression conditions," Fire Safety Journal, vol. 36, no. 7, pp. 641-660, 2001.

[15] V. Novozhilov, "Nonlinear dynamical model of compartment fire flashover," Journal of Engineering Mathematics, vol. 67, no. 4, pp. 387-400, 2010.

[16] R. D. Peacock, P. A. Reneke, R. W. Bukowski, and V. Babrauskas, "Defining flashover for fire hazard calculations," Fire Safety Journal, vol. 32, no. 4, pp. 331-345, 1999.

[17] P. H. Thomas, M. L. Bullen, J. G. Quintiere, and B. J. McCaffrey, "Flashover and instabilities in fire behavior," Combustion and Flame, vol. 38, pp. 159-171, 1980.
[18] W. W. Yuen and W. K. Chow, "The role of thermal radiation on the initiation of flashover in a compartment fire," International Journal of Heat and Mass Transfer, vol. 47, no. 19-20, pp. 42654276, 2004.

[19] C. M. Fleischmann and K. B. McGrattan, "Numerical and experimental gravity currents related to backdrafts," Fire Safety Journal, vol. 33, no. 1, pp. 21-34, 1999.

[20] C. M. Fleischmann, P. J. Pagni, and P. B. Williamson, "Quantitative backdraft experiment," in Proceedings of the 4th International Symposium on Fire Safety Science, pp. 337-348, Ottawa, Canda, July 1994.

[21] D. T. Gottuk, M. J. Peatross, J. P. Farley, and F. W. Williams, "The development and mitigation of backdraft: a real-scale shipboard study," Fire Safety Journal, vol. 33, no. 4, pp. 261-282, 1999.

[22] A. Horvat and Y. Sinai, "Numerical simulation of backdraft phenomena," Fire Safety Journal, vol. 42, no. 3, pp. 200-209, 2007.

[23] W. Weng and W. Fan, "Critical condition of backdraft in compartment fires: a reduced-scale experimental study," Journal of Loss Prevention in the Process Industries, vol. 16, no. 1, pp. 1926, 2003.

[24] W. Weng and W. Fan, "Nonlinear analysis of the backdraft phenomenon in room fires," Fire Safety Journal, vol. 39, no. 6, pp. 447-464, 2004.

[25] R. Yang, W. Weng, W. Fan, and Y. Wang, "Subgrid scale laminar flamelet model for partially premixed combustion and its application to backdraft simulation," Fire Safety Journal, vol. 40, no. 2, pp. 81-98, 2005.

[26] C. R. Barnett, "BFD curve: a new empirical model for fire compartment temperatures," Fire Safety Journal, vol. 37, no. 5, pp. 437-463, 2002.

[27] C. R. Barnett, "Replacing international temperature-time curves with BFD curve," Fire Safety Journal, vol. 42, no. 4, pp. 321-327, 2007.

[28] N. D. Pope and C. G. Bailey, "Quantitative comparison of FDS and parametric fire curves with post-flashover compartment fire test data," Fire Safety Journal, vol. 41, no. 2, pp. 99-110, 2006. 


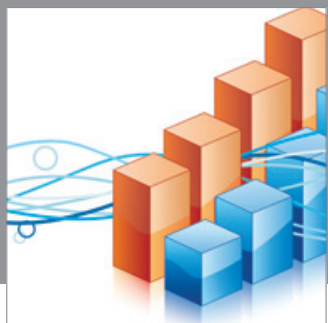

Advances in

Operations Research

mansans

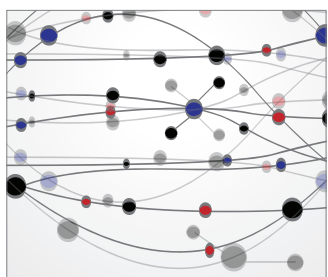

The Scientific World Journal
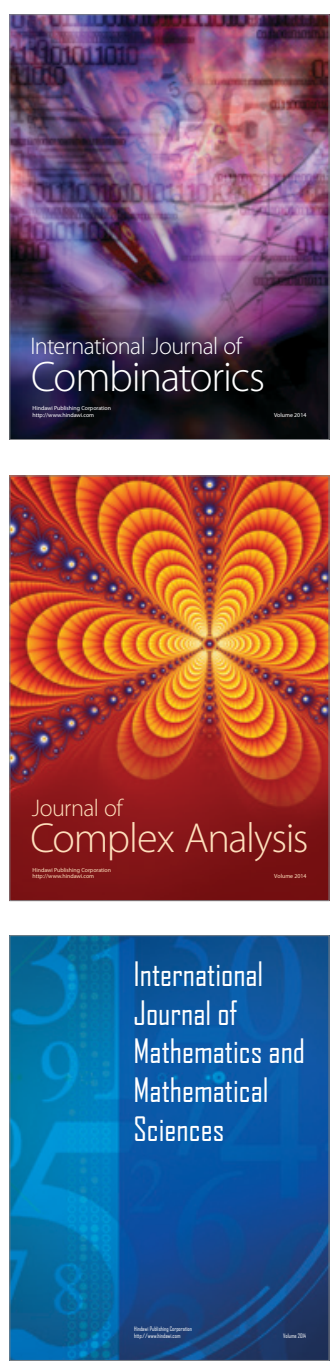
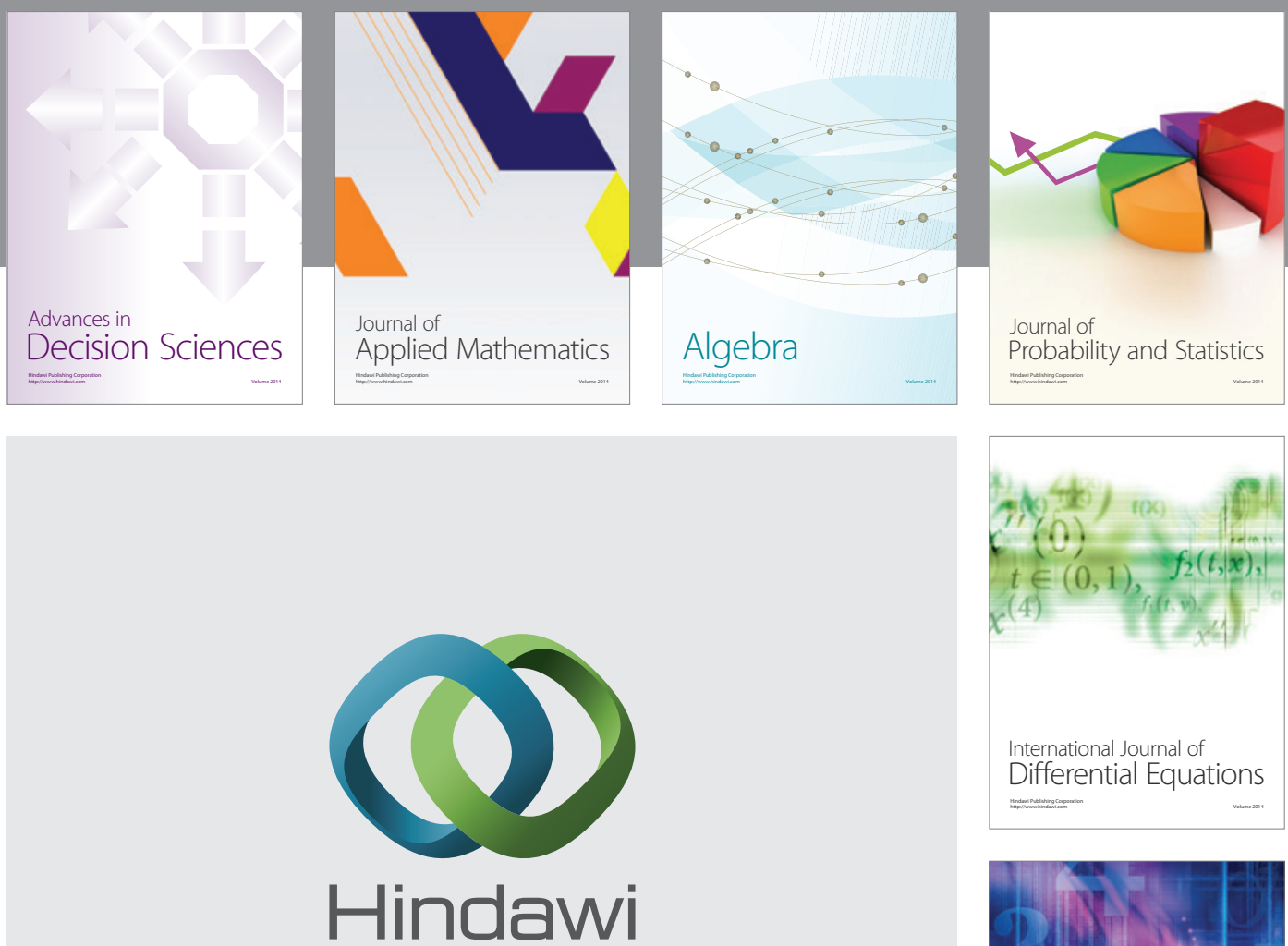

Submit your manuscripts at http://www.hindawi.com
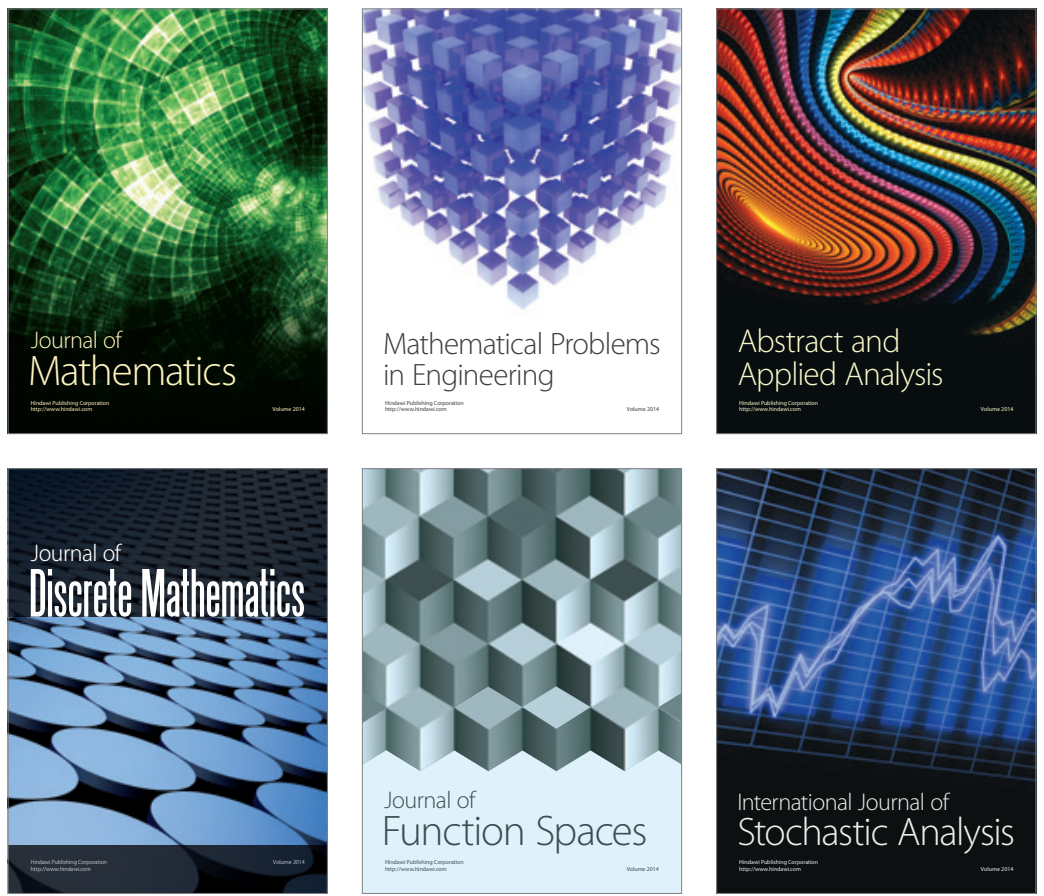

Journal of

Function Spaces

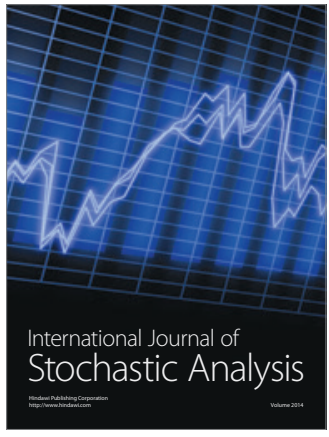

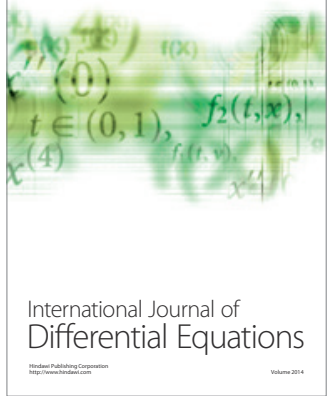
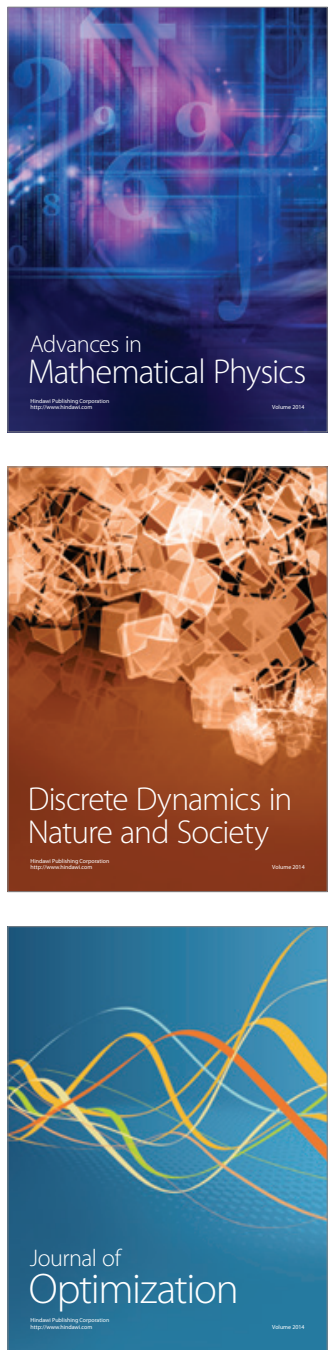